\title{
Low-Intensity Shock Wave Therapy in Sexual Medicine-Clinical Recommendations from the European Society of Sexual Medicine (ESSM)
}

Paolo Capogrosso, MD, Anders Frey, MD, ${ }^{2}$ Christian Fuglesang S. Jensen, MD, ${ }^{3}$ Giulia Rastrelli, MD, $\mathrm{PhD}^{4}$ Giorgio I. Russo, MD, PhD, Josep Torremade, MD, ${ }^{6}$ Maarten Albersen, MD, PhD, ${ }^{7,8}$ llan Gruenwald, MD, ${ }^{9}$ Yacov Reisman, $\mathrm{MD}^{10}$ and Giovanni Corona, $\mathrm{MD}, \mathrm{PhD}^{11}$

\section{ABSTRACT}

Introduction: Low-intensity shockwave therapy (LISWT) has been investigated for the treatment of uroandrological disorders including erectile dysfunction (ED), Peyronie's disease (PD) and chronic prostatitis/chronic pelvic pain syndrome (CP/CPPS) with controversial findings.

Aim: To review the evidence on LISWT for ED, PD, and CP/CPPS and provide clinical recommendations on behalf of the European Society of Sexual Medicine.

Methods: Medline and Embase databases were searched for randomized clinical trials (RCTs), meta-analyses and open-label prospective or retrospective studies investigating the effect of LISWT on ED, PD, or CP/CPPS.

Outcomes: The panel provided statements on clinically relevant questions concerning LISWT: (i) treatment efficacy, (ii) treatment protocol, (iii) clinical indications, and (iv) safety. The level of evidence was provided according to the Oxford 2011 criteria and graded using the Oxford Centre for Evidence-Based Medicine recommendations.

Results: 11 RCTs and 5 meta-analyses investigated LISWT for ED. RCTs provided controversial results on the efficacy of LISWT and were affected by high heterogeneity and the small number of patients included. Pooleddata analysis showed an overall positive effect in terms of erectile function improvement but reported small estimates and included a largely heterogeneous cohort of patients. 4 RCTs and 1 meta-analysis assessed LISWT for PD. All trials showed positive findings in terms of pain relief but no effect on penile curvature and plaque size. Inclusion criteria vary widely among studies, and further investigation is needed. 5 RCTs investigated LISWT for $\mathrm{CP} / \mathrm{CPPS}$. Data showed a possible effect on pain relief, although there is no evidence supporting that pain relief was maintained or any improvement in pain over time.

Clinical Implications: LISWT needs to be further investigated in the context of sexual medicine and is almost but not yet ready for clinical practice.

Strengths and limitations: All studies have been evaluated by a panel of experts providing recommendations for clinical practice.

Conclusions: LISWT is a safe and well-tolerated procedure but its efficacy for the treatment of ED is doubtful and deserves more investigation. Patients reporting pain associated with PD may benefit from LISWT, although no effect is expected on disease progression. LISWT is not a primary treatment for CP/CPPS, but it may be

Received May 18, 2019. Accepted July 18, 2019.

'Department of Urology; Ospedale San Raffaele, Vita-Salute University, Milano, Italy;

${ }^{2}$ Department of Urology, University of Southern Denmark, Esbjerg and Odense, Denmark;

${ }^{3}$ Department of Urology, Herlev and Gentofte Hospital, University of Copenhagen, Copenhagen, Denmark;

${ }^{4}$ Andrology, Female Endocrinology and Gender Incongruence Unit, Department of Experimental, Clinical and Biomedical Sciences, University of Florence, Florence, Italy;

5Urology Section-University of Catania, Catania, Italy;

${ }^{6}$ Hospital Universitari de Bellvitge, Barcelona, Spain;
${ }^{7}$ Laboratory of Experimental Urology, Department of Development and Regeneration, University of Leuven, Leuven, Belgium;

${ }^{8}$ Department of Urology, University Hospitals of Leuven, Leuven, Belgium;

${ }^{9}$ Neuro-urology Unit, Rambam Healthcare Campus, Haifa, Israel;

${ }^{10}$ Men's Health Clinic, Amstelland Hospital, Amsterdam, The Netherlands;

"Endocrinology Unit, Medical Department, Azienda USL, Maggiore-Bellaria Hospital, Bologna, Italy

Copyright (c) 2019, International Society for Sexual Medicine. Published by Elsevier Inc. All rights reserved.

https://doi.org/10.1016/j.jsxm.2019.07.016 
considered as an option to relieve pain. Capogrosso P, Frey A, Jensen CFS, et al. Low-Intensity Shock Wave Therapy in Sexual Medicine-Clinical Recommendations from the European Society of Sexual Medicine (ESSM). J Sex Med 2020;XX:XXX-XXX.

Copyright (C) 2019, International Society for Sexual Medicine. Published by Elsevier Inc. All rights reserved.

Key Words: Shockwave; Erectile Dysfunction; Peyronie's Disease; Chronic Prostatitis

\section{INTRODUCTION}

Low-intensity shockwave therapy (LISWT) is a physical therapy method originally investigated for the treatment of chronic wounds, musculoskeletal diseases, and ischemic myocardial disease. ${ }^{1,2}$ All of these conditions share tissue hypoxia as a main pathogenic factor. The mechanical shear stress provoked by LISWT on the treated tissue was deemed to induce neovascularization and to enhance local blood flow. ${ }^{3}$

In the last decade, LISWT has been tested on several uroandrological diseases, including erectile dysfunction (ED), Peyronie's disease (PD), and chronic prostatitis/chronic pelvic pain syndrome (CP/CPPS). In this context, preclinical animal model studies have assessed the biological effect of LISWT. According to these studies, the molecular mechanisms of LISWT may be related to different pathways of biological reactions: besides triggering neovascularization via the upregulation of the vascular endothelial growth factor and its receptor, ${ }^{4}$ LISWT has been found to promote progenitor cell activation, proliferation, migration, and differentiation in penile tissue. ${ }^{5}$ In vivo studies have demonstrated a differentiation of penile endogenous stem/ progenitor cells toward smooth muscle cells and endothelial cells after localized LISWT treatment, resulting in a restoration of cavernosal tissue architecture in rat models of ED characterized by penile fibrosis and impaired vascularization. ${ }^{5}$ In an animal model of cavernous nerve injury, LISWT was able to induce nerve regeneration by enhancing the recruitment and the activation of progenitor Schwann cells. ${ }^{6}$ In the context of PD, it has been suggested that LISWT may exert a direct mechanical effect, thus, remodeling the penile plaque; moreover, the increase in local blood circulation could lead to the enhancement of inflammation and macrophage activity resulting in plaque lysis. Finally, LISWT induced hyperstimulation of nociceptors, interrupting the flow of the nerve impulses responsible for pain in patients with CPPS, ${ }^{8}$ and may reduce the perineal muscle tone and spasticity when applied to the perineum. ${ }^{8}$ However, all of these findings deserve further investigation to come to any final conclusions.

Although several randomized clinical trials (RCTs) and metaanalyses have investigated the role of LISWT for the treatment of $\mathrm{ED}, \mathrm{PD}$, and CPPS, the clinical significance of this treatment method remains controversial within the scientific community. In this article, we aim to review the evidence on LISWT for ED, $\mathrm{PD}$, and $\mathrm{CP} / \mathrm{CPPS}$, and we propose position statements for the use of LISWT in clinical practice on behalf of the European Society of Sexual Medicine.

\section{METHODS}

\section{Evidence Acquisition}

\section{Literature Search and Study Eligibility}

We searched Medline and Embase using the terms (("erectile dysfunction" OR "erectile function" OR "peyronie*” OR "prostate" OR "pain" OR "prostatitis" OR "chronic pelvic pain syndrome") AND (shockwave OR shock)). For the specific purpose of this study, RCTs and open-label prospective or retrospective studies investigating the effect of LISWT for the treatment of either ED, PD, or CP/CPPS (in the period of June 2018-December 2018) were included.

\section{Data Extraction}

Studies were categorized according to the specific fields of investigation (eg, ED, PE, or PDs). Data regarding the study design, population baseline characteristics and treatment protocol were collected. The following outcomes were analyzed for each specific disease: (i) ED-International Index of Erectile Function (IIEF), Erection Hardness Scale (EHS), penile Doppler ultrasound findings; (ii) PD-IIEF, plaque size, penile curvature, pain; and (iii) CP/CPPS-National Institute of Health-Chronic Prostatitis Symptom Index (NIH-CPSI) International Prostatic Symptoms Score, pain. The Cochrane Collaboration risk of bias tool was used to assess risk of bias for RCTs.

\section{Review Methods}

Abstracts were reviewed by the 3 different subgroups of the panel for relevance to the defined review question (ED: P.C., C.F.S.J., A.F.; PD: J.T.; CPPS: G.I.R., G.R.). If it was not clear from the abstract whether the article might contain relevant data, the full article was assessed. Thereafter, relevant studies were analyzed and summarized after an interactive peer-review process of the panel. Results of RCTs were considered to provide clinical statements on the use of LISWT for the treatment of the investigated diseases. When the evidence from RCTs was not enough to draw conclusions for clinical practice, data from nonrandomized cohort studies were assessed. The panel identified specific clinically relevant questions concerning LISWT for which statements need to be provided: (i) treatment efficacy; (ii) treatment protocol; (iii) clinical indications; and (iv) safety. The statements were internally discussed, and the level of evidence was provided according to the Oxford 2011 Levels of Evidence criteria (https://www.cebm.net/2009/06/oxford-centre-evidencebased-medicine-levels-evidence-march-2009/); moreover, the quality of evidence was graded by applying the Oxford Centre for 
Evidence-Based Medicine recommendations. No recommendations were given when the available data were insufficient to draw conclusions. Disagreements were resolved by consensus.

\section{ERECTILE DYSFUNCTION}

\section{Statements}

Treatment Efficacy

Patient-reported outcomes (IIEF, EHS). Current evidence is promising but is still controversial; therefore, a clear clinical recommendation of LISWT for ED cannot be made, and more high-quality studies are needed.

Penile hemodynamics. LISWT significantly improves penile hemodynamic parameters of patients with vasculogenic ED. However, the clinical long-term significance of this improvement is uncertain (level 2; grade C).

Effect endurance. Current data suggest a variable effect of LISWT on EF up to 12 months after treatment (level 2; grade C). More data are needed to assess the longer-term effects of LISWT.

\section{Treatment Protocol}

Energy source and type of SW (linear vs focused). Currently, there are no studies comparing the 2 treatment methods. Further research should address the possible differences between focused and linear SW.

\section{Settings and Protocol}

There are only few data comparing different treatment protocols with the same SW generator; therefore, a specific protocol cannot be suggested.

\section{Indication}

LISWT for patients with vasculogenic ED, either treatmentnaïve, responders or non-responders to phosphodiesterase type 5 inhibitors (PDE5is), shows encouraging results, but unambiguous evidence for efficacy is lacking, pooled effect size is modest, and evidence quality is low. Patients should be informed about the conflicting results regarding efficacy of this treatment when discussing LISWT (level 2; grade D).

Safety. LISWT is a safe and well-tolerated procedure without clinically significant adverse events (level 1; grade A).

\section{Evidence}

Treatment Efficacy

Patient-reported outcomes. To date 11 RCTs have investigated the clinical effects of LISWT on EF (Table 1). Among them, the study by Srini and colleagues 9 suffers from high risk of bias due to a drop-out rate of $37 \%$ in the treatment group and $58 \%$ in the placebo group, casting doubts on the reliability of their findings (Table 2). Likewise, the multicenter trial conducted by Motil and coworkers ${ }^{10}$ suffers from a poor description of methodology, which results in a high risk of bias; moreover, the authors reported changes in the outcome without applying any statistical test for significance. 7 of the remaining studies were sham-controlled trials ${ }^{11-17}$ and were considered by the committee to assess treatment efficacy. Of them, 3 trials $^{11,14,16}$ reported statistically significant results with regard to IIEF-EF and EHS improvement, 2 trials showed no difference, ${ }^{13,15}$ whereas 2 studies $^{12,17}$ reported a significant improvement for only 1 of the investigated outcomes (eg, EHS or IIEF-EF).

Among the trials showing a positive effect of LISWT on EF, there is the first published RCT, ${ }^{11}$ which included a total of 60 patients. The mean change from baseline IIEF-EF score after 1 month of follow-up was 6.7 points in the treatment group $(\mathrm{n}=40)$ and 3 points in the sham treatment group $(\mathrm{n}=20)(P=$ $.03)$, whereas the rate of patients reporting an EHS 3-4 score (meaning an erection hard enough for penetration) was $78 \%$ in the treatment group compared with $35 \%$ in the sham treatment group. Likewise, in 2016 Kitrey and coworkers ${ }^{14}$ conducted an RCT on 55 patients (treatment group $\mathrm{n}=37$ and sham treatment group $n=18$ ): at 1 month from the end of treatment, the median change from baseline in the IIEF-EF score was 5 points in the treatment group and 0 points in the sham treatment group $(P=$ $.0006)$, whereas the rate of EHS 3 was $54 \%$ in the treatment group vs $0 \%$ in the sham treatment group $(P<.0001)$. Interestingly, the authors reported that $40.5 \%$ of patients in the LISWT group showed a clinically meaningful EF improvement according to the minimum clinically important differences (MCID) criteria compared with none in the sham treatment group. In a more recent double-blind trial, changes in the IIEF-EF score were assessed as a secondary outcome in 30 patients treated with LISWT as compared with 16 sham-treated control subjects. ${ }^{16}$ The authors performed repeated follow-up assessments, showing no significant difference in the change of the IIEF-EF score after 1 month of follow-up, whereas significant results favoring treatment were observed at 3, 6, 9, and 12 months. The MCID criteria were met in $75 \%$ of patients in the LISWT group vs $12.5 \%$ in the sham treatment group at 12 months. Similar findings were reported by Yamaçake et $\mathrm{al}^{17}$ investigating the effect of LISWT among kidney transplanted men with ED: they reported a 5-point increase of the IIEF-EF in 70\% of patients in the treatment group vs only $10 \%$ in the sham treatment group.

In 2014, Yee et $\mathrm{al}^{13}$ published their RCT on LISWT for ED. Based on a power calculation, a total of 70 patients needed to be enrolled; however, only 58 patients completed the trial (treatment group $n=30$ and sham treatment group $n=28$ ). After 1 month of follow-up, there was no difference in the IIEF-EF or EHS scores. Likewise, Fojecki and coworkers, ${ }^{15}$ in a cohort of 118 patients (treatment group $\mathrm{n}=58$ and sham treatment group $\mathrm{n}=$ 60 ), showed no statistically significant changes in the IIEF-EF 
Table 1. Randomized clinical trials investigating LISWT for ED

\begin{tabular}{|c|c|c|c|c|c|c|c|}
\hline Study & $\begin{array}{l}\text { No. treated/ } \\
\text { No. control }\end{array}$ & Characteristics of patients & Comparator & $\begin{array}{l}\text { Study } \\
\text { duration }\end{array}$ & $\begin{array}{l}\text { ESWT } \\
\text { protocol }\end{array}$ & $\begin{array}{l}\text { Summary of results } \\
\text { (IIEF-EF and EHS) }\end{array}$ & $\begin{array}{l}\text { Adverse } \\
\text { events }\end{array}$ \\
\hline Vardi et $\mathrm{al}^{71}$ & $40 / 20$ & $\begin{array}{l}\text { Vasculogenic } \\
\text { PDE5i responders }\end{array}$ & Sham therapy & $1 \mathrm{mo}$ & $\begin{array}{l}\text { Medispec } \\
12 \text { sessions } 1500 \mathrm{sw} \\
0.09 \mathrm{~mJ} / \mathrm{mm}^{2} \\
120 \mathrm{sw} / \mathrm{min}^{2}\end{array}$ & $\begin{array}{l}\text { IIEF-EF change: } \\
6.7 \text { points in treatment group; } \\
3.0 \text { points in sham group } \\
\text { Rate of EHS 3-4: } \\
78 \% \text { in treatment group; } \\
35 \% \text { in sham group }\end{array}$ & None \\
\hline Olsen et $\mathrm{al}^{12}$ & $51 / 54$ & $\begin{array}{l}\text { Vasculogenic } \\
\text { PDE5i responders }\end{array}$ & Sham therapy & 6 wks & $\begin{array}{l}\text { Storz } \\
12 \text { sessions; } 3000 \mathrm{sw} \\
0.15 \mathrm{~mJ} / \mathrm{mm}^{2} \\
240 \mathrm{sw} / \mathrm{min}\end{array}$ & $\begin{array}{l}\text { IIEF-EF change: non-significant } \\
\text { Rate of EHS 3-4: } \\
57 \% \text { in treatment group; } \\
9 \% \text { in sham group }\end{array}$ & None \\
\hline Yee et $\mathrm{al}^{13}$ & $30 / 28$ & $\begin{array}{l}\text { Vasculogenic } \\
\text { Response to PDE5i } \\
\text { treatment not reported }\end{array}$ & Sham therapy & $1 \mathrm{mo}$ & $\begin{array}{l}\text { Medispec } \\
12 \text { sessions; } 1500 \mathrm{sw} \\
0.09 \mathrm{~mJ} / \mathrm{mm}^{2} \\
120 \mathrm{sw} / \mathrm{min}^{2}\end{array}$ & $\begin{array}{l}\text { IIEF-EF change: non-significant } \\
\text { EHS score change: } \\
\text { non-significant }\end{array}$ & None \\
\hline Srini et $\mathrm{al}^{9}$ & $60 / 17$ & $\begin{array}{l}\text { Vasculogenic } \\
\text { PDE5i responders }\end{array}$ & Sham therapy & $12 \mathrm{mos}$ & $\begin{array}{l}\text { Medispec } \\
12 \text { sessions; } 1500 \mathrm{sw} \\
0.09 \mathrm{~mJ} / \mathrm{mm}^{2} \\
\quad 120 \mathrm{sw} / \mathrm{min}^{2}\end{array}$ & $\begin{array}{l}\text { IIEF-EF change: } \\
8.7 \text { points in treatment group } \\
\text { Rate of EHS 3-4: } \\
83 \% \text { in treatment group }\end{array}$ & None \\
\hline Kitrey et $\mathrm{al}^{14}$ & $37 / 18$ & $\begin{array}{l}\text { Vasculogenic } \\
\text { PDE5i non-responders }\end{array}$ & Sham therapy & $1 \mathrm{mo}$ & $\begin{array}{l}\text { Medispec } \\
12 \text { sessions; } 1500 \mathrm{sw} \\
0.09 \mathrm{~mJ} / \mathrm{mm}^{2} \\
\quad 120 \mathrm{sw} / \mathrm{min}^{2}\end{array}$ & $\begin{array}{l}\text { IIEF-EF change: } \\
5 \text { points in treatment group; } \\
0 \text { points in sham group } \\
\text { Rate of EHS 3-4: } \\
54 \% \text { in treatment group; } \\
0 \% \text { in sham group }\end{array}$ & None \\
\hline Fojecki et $\mathrm{al}^{15}$ & $58 / 60$ & $\begin{array}{l}\text { Vasculogenic: } \\
\text { Mixed PDE5i } \\
\text { responders and PDE5i } \\
\text { non-responders }\end{array}$ & Sham therapy & 6 wks & $\begin{array}{l}\text { Wolf } \\
5 \text { sessions; } 600 \mathrm{sw} \\
0.09 \mathrm{~mJ} / \mathrm{mm}^{2} \\
5 \mathrm{~Hz}\end{array}$ & $\begin{array}{l}\text { IIEF-EF change: non-significant } \\
\text { Rate of EHS 3-4: non-significant }\end{array}$ & None \\
\hline Motil et $\mathrm{al}^{10}$ & $75 / 50$ & $\begin{array}{l}\text { Vasculogenic } \\
\text { PDE5i responders }\end{array}$ & $\begin{array}{l}\text { Device in off-mode } \\
\text { with speakers } \\
\text { playing sounds } \\
\text { from on-mode }\end{array}$ & $1 \mathrm{mo}$ & $\begin{array}{l}\text { Wolf } \\
4 \text { sessions; 4,000 sw } \\
0.16 \mathrm{~mJ} / \mathrm{mm}^{2} \\
480 \mathrm{sw} / \mathrm{min}^{2}\end{array}$ & $\begin{array}{l}\text { No statistical analyses } \\
\text { performed } \\
\text { MCID based on IIEF-EF score } \\
\text { reached in } 81 \% \text { of } \\
\text { treated men }\end{array}$ & None \\
\hline $\begin{array}{l}\text { Kalyvianakis } \\
\text { et } \mathrm{al}^{16}\end{array}$ & $30 / 16$ & $\begin{array}{l}\text { Vasculogenic } \\
\text { PDE5i responders }\end{array}$ & Sham therapy & $12 \mathrm{mos}$ & $\begin{array}{l}\text { Medispec } \\
12 \text { sessions; } 1,500 \mathrm{sw} \\
0.09 \mathrm{~mJ} / \mathrm{mm}^{2} \\
120 \mathrm{sw} / \mathrm{min}^{2}\end{array}$ & $\begin{array}{l}\text { MCID based on IIEF-EF score } \\
\text { reached in } 75 \% \text { vs } 25 \% \text { in } \\
\text { treatment and sham } \\
(P=.005) \text { at } 12 \mathrm{mos}\end{array}$ & None \\
\hline
\end{tabular}

(continued) 


\begin{tabular}{|c|c|c|c|c|c|c|c|}
\hline Study & $\begin{array}{l}\text { No. treated/ } \\
\text { No. control }\end{array}$ & Characteristics of patients & Comparator & $\begin{array}{l}\text { Study } \\
\text { duration }\end{array}$ & $\begin{array}{l}\text { ESWT } \\
\text { protocol }\end{array}$ & $\begin{array}{l}\text { Summary of results } \\
\text { (IIEF-EF and EHS) }\end{array}$ & $\begin{array}{l}\text { Adverse } \\
\text { events }\end{array}$ \\
\hline $\begin{array}{l}\text { Kalyvianakis } \\
\text { et } \mathrm{al}^{24}\end{array}$ & $42 / 0$ & $\begin{array}{l}\text { Vasculogenic } \\
\text { PDE5i responders }\end{array}$ & $\begin{array}{l}6 \text { sessions vs } 12 \\
\text { sessions and } 12 \\
\text { sessions vs } 18 \\
\text { sessions }\end{array}$ & $\begin{array}{c}6 \text { and } 12 \\
\text { mos }\end{array}$ & $\begin{array}{l}\text { Dornier } \\
12 \mathrm{sessions} ; 5,000 \mathrm{sw} \\
0.05 \mathrm{~mJ} / \mathrm{mm}^{2} \\
250 \mathrm{sw} / \mathrm{min}^{2} \\
8 \mathrm{hz} \mathrm{vs} \\
18 \mathrm{sessions} ; 5000 \mathrm{sw} \\
0.05 \mathrm{~mJ} / \mathrm{mm}^{2} \\
250 \mathrm{sw} / \mathrm{min} \\
8 \mathrm{hz}\end{array}$ & $\begin{array}{l}\text { IIEF-EF change: non-significant } \\
\text { difference between groups }\end{array}$ & None \\
\hline Fojecki et $\mathrm{al}^{18}$ & $95 / 0$ & $\begin{array}{l}\text { Vasculogenic: } \\
\text { Mixed PDESi responders and } \\
\text { PDESi non-responders }\end{array}$ & $\begin{array}{l}5 \text { sessions vs } 10 \\
\text { sessions }\end{array}$ & $\begin{array}{c}6 \text { and } 12 \\
\text { mos }\end{array}$ & $\begin{array}{l}\text { Wolf } \\
5 \text { sessions; } 600 \mathrm{sw} \\
0.09 \mathrm{~mJ} / \mathrm{mm}^{2} \\
5 \mathrm{~Hz} \text { vs } \\
10 \mathrm{sessions} ; 600 \mathrm{sw} \\
0.09 \mathrm{~mJ} / \mathrm{mm}^{2} \\
5 \mathrm{~Hz}\end{array}$ & $\begin{array}{l}\text { IIEF-EF change: non-significant } \\
\text { Rate of EHS 3-4: non-significant }\end{array}$ & None \\
\hline $\begin{array}{l}\text { Yamaçake } \\
\text { et al }{ }^{17}\end{array}$ & $10 / 10$ & $\begin{array}{l}\text { Kidney transplanted men } \\
\text { with ED }\end{array}$ & Sham therapy & $\begin{array}{l}1,3 \text { and } 12 \\
\text { mos }\end{array}$ & $\begin{array}{l}\text { Electro Medical Systems } \\
6 \text { sessions; } 2,000 \mathrm{sw} \\
0.09 \mathrm{~mJ} / \mathrm{mm}^{2}\end{array}$ & $\begin{array}{l}\text { IIEF-EF change: } \\
70 \% \text { vs } 10 \% \text { achieved } \\
5 \text { points increase in the } \\
\text { treatment vs sham } \\
\text { Rate of EHS 3-4: non-significant }\end{array}$ & None \\
\hline
\end{tabular}

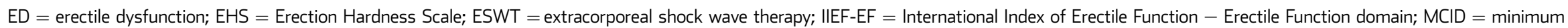
clinically important differences; PDESis = phosphodiesterase type 5 inhibitors; sw = shock waves. 
Table 2. The Cochrane Collaboration's tool for assessing risk of bias

\begin{tabular}{|c|c|c|c|c|c|c|c|}
\hline & $\begin{array}{l}\text { Random sequence } \\
\text { generation }\end{array}$ & $\begin{array}{l}\text { Allocation } \\
\text { concealment }\end{array}$ & $\begin{array}{l}\text { Blinding of participants } \\
\text { and personnel }\end{array}$ & $\begin{array}{l}\text { Blinding of outcome } \\
\text { assessment }\end{array}$ & $\begin{array}{l}\text { Incomplete } \\
\text { outcome data }\end{array}$ & $\begin{array}{l}\text { Selective } \\
\text { reporting }\end{array}$ & $\begin{array}{l}\text { Other sources } \\
\text { of bias }\end{array}$ \\
\hline \multicolumn{8}{|l|}{ Erectile dysfunction } \\
\hline Vardi et al ${ }^{17}$ & Yes & NR & Yes & NR & Yes & No & - \\
\hline Olsen et $\mathrm{al}^{12}$ & No & Yes & Yes & NR & Yes & No & - \\
\hline Yee et $\mathrm{al}^{13}$ & Yes & Yes & Yes & NR & Yes & No & - \\
\hline Srini et $\mathrm{al}^{9}$ & NR & Yes & NR & Yes & Yes & No & High drop-out rate \\
\hline Kitrey et $\mathrm{al}^{14}$ & NR & NR & Yes & NR & Yes & No & - \\
\hline Fojecki et $\mathrm{al}^{15}$ & Yes & Yes & Yes & Yes & Yes & No & \\
\hline Motil et $\mathrm{al}^{10}$ & NR & NR & NR & NR & NR & No & - \\
\hline Kalyvianakis et $\mathrm{al}^{16}$ & Yes & NR & Yes & NR & No & No & - \\
\hline Yamaçake et $\mathrm{al}^{17}$ & Yes & Yes & No & Yes & No & No & - \\
\hline \multicolumn{8}{|l|}{ Peyronie's disease } \\
\hline Palmieri et $\mathrm{al}^{37}$ & NR & Yes & Yes & NR & Yes & No & - \\
\hline Chitale et $a^{38}$ & Yes & Yes & Yes (participants) & Yes & Yes & No & - \\
\hline Hatzichristodoulou et $\mathrm{al}^{39}$ & Yes & Yes & Yes (participants) & NR & Yes & No & - \\
\hline \multicolumn{8}{|l|}{ Chronic prostatitis } \\
\hline Zimmermann et $\mathrm{al}^{45}$ & NR & NR & Yes & Yes & NR & No & - \\
\hline Zeng et $a^{46}$ & Yes & NR & No & Yes & No ITT & No & - \\
\hline Vahdatpour et $a^{47}$ & NR & NR & No & No & NR & No & - \\
\hline Pajovic et $a^{49}$ & NR & NR & No & No & NR & No & - \\
\hline Moayednia et $a^{48}$ & NR & NR & No & NR & Yes & Nor & - \\
\hline
\end{tabular}

$\mathrm{ITT}=$ intention to treat; NR = not reported. 
score after 5 weeks from the end of treatment. In this case, the study met the number of patients needed to detect a significant difference between the 2 groups. After the initial 5 weeks of treatment, both groups received an additional 5 weeks of active treatment: no differences were found in either IIEF-EF or EHS scores at 10 weeks' follow-up. In a later publication, ${ }^{18}$ the same group presented the 6-and 12-month follow-up data from the same trial, again showing no difference in the investigated outcomes. However, it should be noted that, in this trial, the authors applied a gel pad delivering the shockwaves (SW) at skin level, which could have led to suboptimal treatment because of poor penetration of the energy into the tissues. ${ }^{18}$

In the last trial, ${ }^{12} 104$ patients were enrolled (treatment group $\mathrm{n}=51$ and sham treatment group $\mathrm{n}=54$ ) meeting the required number of 100 patients according to their power analysis. Unfortunately, the randomization was broken after 10 weeks, and the only available follow-up assessment was at 5 weeks from the end of treatment. No difference was observed in the IIEF-EF domain score changes between the LISWT and the sham treatment group, whereas the rate of EHS 3-4 was $57 \%$ in the treatment group vs $9 \%(P=.0001)$ in the sham treatment group.

5 meta-analyses have investigated the effect of LISWT on ED (Table 3). Of them, 3 studies included heterogeneous populations of patients with ED or ED associated with PD or CPPS, thus, making it difficult to interpret the results on EF outcomes. ${ }^{19-21}$ Moreover, only 2 meta-analyses included exclusively RCTs: Man et $\mathrm{al}^{21}$ analyzed data from 9 studies reporting an overall mean difference (MD) in the IIEF-EF score after treatment of 2.54 (95\% CI 0.83-4.25; $P=.004)$ compared with the sham treatment group and a risk difference in the EHS of 0.46 (95\% CI 0.04-0.88; $P=.03$ ). Likewise, Clavijo et $\mathrm{al}^{22}$ pooled data from RCTs conducted in patients with ED only. They reported a strong trend toward a higher MD in the IIEFEF of 4.17 (95\% CI -0.5 to 8.3) favoring LISWT-treated men. However, in this meta-analysis the authors included a study based on pooled data of 5 previously published RCTs, thus, resulting in a double inclusion of positive trials with a possible overestimation of the effect size. Significant findings in terms of IIEF-EF improvement were reported also in the other metaanalyses, ${ }^{1,20}$ except for Zou et al, ${ }^{23}$ who observed only a significant improvement in the EHS score (relative risk: 8.31; 95\% CI 3.88-17.78; $P<.00001$ ).

Penile hemodynamics. Changes in penile hemodynamics, as assessed with penile Duplex ultrasound scanning, have been reported in 3 sham-controlled trials. ${ }^{11,14,16}$ All of them showed a significant improvement in penile blood flow in the actively treated group as compared with control subjects.

Effect endurance. All studies suffer from short follow-up, ranging from 1-12 months. In 1 non-sham-controlled trial, Kalyvianakis and coworkers ${ }^{24}$ randomized 42 patients to 
either 6 or 12 sessions of LISWT, with a repeated 6-session treatment course after 6 months; results suggested that repeating LISWT after 6 months could further improve the efficacy. 1 single-arm cohort study reported 2-year follow-up data, ${ }^{25}$ showing a $50 \%$ decrease in the percentage of patients who were responders to LISWT at previous follow-up, according to the MCID criteria.

\section{Treatment Protocol}

Energy source and type of SW (linear vs focused). Several types of SW generators have been used; most of the studies were performed with focused SW generators, and only 2 RCTs used a linear generator. ${ }^{10,15}$ There are no data directly comparing the 2 types of generators; in 1 meta-analysis the authors performed a sub-group analysis according to the type of generators used, reporting a significant improvement of the IIEF-EF only for studies applying focused SWs. ${ }^{21}$ Overall, current evidence is too limited to draw final conclusions on the best SW generator.

Settings and protocol. Treatment protocols vary widely among RCTs in terms of either energy flux density (EFD), number of SWs per session, and length of treatment. There are no studies directly comparing different protocols. According to the meta-analysis by Man et $\mathrm{al}^{21}$ an $\mathrm{EFD}=0.09 \mathrm{~mJ} / \mathrm{mm}^{2}$ was superior to other protocols. They also found a better effect associated with a greater number of SW and a treatment duration $<6$ weeks. In the meta-analysis by $\mathrm{Lu}$ et $\mathrm{al}^{, 20}$ no significant difference was observed between investigated EFDs, but they confirmed that a higher number of SWs seems to improve the effect and that the optimal treatment should last $<6$ weeks. Clavijo et $\mathrm{al}^{22}$ found $18,000 \mathrm{SWs}$ to be better than 6,000 SWs. Conversely, the meta-analysis by Zou et $\mathrm{al}^{23}$ found no measurable difference between protocols.

\section{Indication}

All RCTs included patients with vasculogenic ED with mild to severe levels of the disease. 1 RCT included only patients who were non-responders to PDE5is, showing significant improvement of EF compared with the sham-treated group. ${ }^{14}$ A mixed population of both responders and non-responders to PDE5is were included in another positive trial. ${ }^{16}$ Data from metaanalyses showed controversial findings: Man et $\mathrm{al}^{21}$ found a statistically significant EF improvement in patients with mild and severe ED; moreover, patients who used PDE5is during treatment showed better results than those who did not. Lu et $\mathrm{al}^{20}$ reported a significant EF improvement only for patients with mild ED and for patients using PDE5is. Moreover, in a small single-arm study, younger age (OR 0.85 , 95\% CI 0.76-0.95) and the level of comorbidities (OR 0.02, 95\% CI 0.00-0.98) were associated with a higher chance of achieving an EHS of 3-4 at 1 month after treatment. ${ }^{26}$ However, these findings warrant confirmation in RCTs.
Safety

No adverse events (AEs) have been reported in shamcontrolled trials. Similarly, data from non-randomized, singlearm cohort studies showed no AEs associated with LISWT for ED. ${ }^{25-36}$

\section{Values}

Several RCTs provided evidence on the efficacy of LISWT with conflicting results. Most of them have a low risk of bias and have been conducted in a double-blind fashion, although the blinding methodology has rarely been described in detail. Pooled data from meta-analyses including RCTs showed an overall positive effect in terms of IIEF-EF score improvement, although the estimates are small (ranging from about $2-4$ points of the IIEF-EF) and the heterogeneity high.

\section{Remarks}

In light of the small number of patients included in the RCTs, the heterogeneity among treatment protocols, along with the controversial findings and the off-label indication, the panel recommends limiting this therapy to subjects with vasculogenic ED, and it should be performed preferably in highly specialized centers with documented experience with this type of therapy. Patients should be aware that the scientific evidence is controversial and that the expected improvement may not be clinically relevant, given the small number of reported changes in the IIEFEF score by most of the trials.

\section{PEYRONIE'S DISEASE}

\section{Statements}

\section{Treatment efficacy}

Curvature. Current data do not support the use of LISWT to reduce curvature (level 2; grade $\mathrm{B}$ ).

Plaque size. Current data do not support the use of LISWT to reduce or stabilize plaque size (level 2; grade B).

Pain. LISWT could be an option to reduce pain. However, patients should be carefully counseled that no effect should be expected on curvature and plaque size (level 2; grade B).

\section{Treatment Protocol}

No recommendation can be given on energy source and protocol. Further studies are needed.

Indication. LISWT can be proposed as an option to reduce pain in patients with either acute or stable PD (level 2; grade B).

Safety. LISWT is a well-tolerated procedure without severe adverse events (level 2; grade B). 


\section{Evidence}

\section{Treatment Efficacy}

4 RCTs were included in the analysis on the efficacy of extracorporeal shock wave therapy in PD. ${ }^{37-40}$ Of them, 3 were sham-controlled trials, whereas 1 study compared LISWT with the combination of LISWT + tadalafil. ${ }^{40}$ The summary of baseline characteristics and results of RCTs in PD are reported in Table 4.

Mean curvature degree and plaque size were unchanged in 2 RCTs, including only patients with stable disease. ${ }^{38,39}$ In 1 trial including patients reporting a PD onset $<12$ months, the authors observed a small decrease in curvature and plaque size in the LISWT group $\left(-1.4^{\circ}\right.$ and $-0.6 \mathrm{~cm}^{2}$, respectively), which was statistically significant compared with the small increase in curvature and plaque size observed in the sham group $\left(1.8^{\circ}\right.$ and $0.1 \mathrm{~cm}^{2}$, respectively). ${ }^{37}$ The same group performed a further RCT comparing LISWT vs LISWT + tadalafil $5 \mathrm{mg}$ once daily: no significant effect was observed in terms of curvature and plaque size in both groups.

Palmieri et $\mathrm{al}^{37}$ reported a significantly greater improvement in the visual analogue score (VAS) for LISWT than placebo at 12 $(-3.9$ vs -0.2$)$ and 24 weeks $(-5.1$ vs -2.5$)$ of follow-up in patients with PD of a relatively recent onset ( $<12$ months). Conversely, Chitale and colleagues ${ }^{38}$ did not find significant differences in VAS scores after 6 months from the end of treatment in a group of patients with stable disease for $\geq 6$ months. In a trial including patients with stable PD for 3 months and an overall disease duration $>12$ months, the authors reported a subgroup analysis of patients experiencing pain at baseline: VAS scores were significantly lower in the LISWT group as compared with the sham treatment (VAS reduction from baseline $85 \%$ vs $48 \%$ ). ${ }^{39}$

Gao et al ${ }^{41}$ performed a meta-analysis including RCTs, cohort studies and case-control studies. Pooled data analysis showed a higher chance of observing a lessening of the plaque (OR 2.07; 95\% CI 1.11-3.85; $P=.02$ ), relief of pain (OR 4.46; 95\% CI $2.29-8.68 ; P=.0001)$ and complete remission of pain (OR 5.86; $95 \%$ CI 2.66-12.92; $P=.0001$ ) in the LISWT group compared with control subjects. However, insignificant differences were found in improvement of penile curvature (OR 1.88; 95\% CI 0.97-3.65; $P=.06$ ) and sexual function (OR 2.22; $95 \%$ CI $0.69-7.11 ; P=.18) .{ }^{40}$

\section{Treatment Protocol}

Concerning the energy delivered for PD treatment, there are no data comparing different treatment protocols and energy sources.

\section{Indication}

Overall, 2 RCTs included patients with pain in the early acute phase of the disease, ${ }^{37,40}$ whereas, in the other trials, only patients with a stable PD were enrolled. ${ }^{38,39}$ According to these data, the presence of pain should drive the indication for LISWT rather than the disease phase.
Safety

To assess the safety and tolerability of LISWT for PD, 4 RCTs and 3 non-randomized, controlled studies ${ }^{42-44}$ comparing LISWT with other treatments or sham treatment were considered. Mirone et $\mathrm{al}^{42}$ reported petechiae along the wave direction on the penile surface in $8.5 \%$ of cases. Likewise, Hauck et $\mathrm{al}^{43}$ reported skin hemorrhage (7\%) and slight urethral bleeding (21\%). In another study, local petechial bleeding $(80.7 \%)$ and small ecchymosis (4.9\%) were observed in the LISWT group but resolved spontaneously. ${ }^{39}$ No serious AEs were reported.

\section{Value}

Based on 3 sham-controlled trials of moderate quality, the panel does not recommend the use of LISWT to reduce curvature or plaque size in patients with PD. All trials showed positive findings in terms of pain relief for patients complaining of this symptom. However, patients should be advised that pain usually resolves spontaneously with time and that LISWT is not expected to modify the natural progression of the disease. In addition, LISWT still represents an off-label approach for PD.

\section{Remarks}

Data available from RCTs in PD are heterogeneous: patient inclusion criteria vary from stable disease to non-stable disease, with a history of previous unsuccessful oral medical therapy or without previous PD treatments. Follow-up assessment varies from 24 weeks to 1 year. Different energy sources and protocols are proposed without direct comparison. Further studies are needed to confirm these findings.

\section{CHRONIC PELVIC PAIN SYNDROME}

\section{Statements}

\section{Treatment Efficacy}

Pain. LISWT is an option to consider with the aim of improving prostatitis-like symptoms in patients with CP/CPPS. However, due to the limited evidence from clinical trials and the off-label nature of this treatment, LISWT should not be considered the primary treatment for CP/CPPS (level 2; grade B).

Effect endurance. Clinical benefit from LISWT in terms of symptom improvement could be expected after 12 weeks (level 2; grade B), but its longer-term maintenance has not been proven.

Other outcomes. No specific recommendation could be made regarding the effects of LISWT in men with CP/CPPS with regard to non-symptomatic outcomes, ie, objective measures of prostate health. 


\begin{tabular}{|c|c|c|c|c|c|c|c|}
\hline Study & $\begin{array}{l}\text { No. } \\
\text { treated/ } \\
\text { No. control }\end{array}$ & $\begin{array}{l}\text { Characteristics of } \\
\text { patients }\end{array}$ & Comparator & $\begin{array}{l}\text { Study } \\
\text { duration }\end{array}$ & ESWT protocol & Summary of results & Adverse events \\
\hline Palmieri et $\mathrm{al}^{37}$ & $50 / 50$ & $\begin{array}{l}\text { Acute Peyronie's disease } \\
\text { (onset }<12 \text { mo). } \\
\text { Without previous } \\
\text { PD-treatments }\end{array}$ & Sham-therapy & 6 months & $\begin{array}{l}\text { Storz Duolith (Storz Medical } \\
\text { AG, Switzerland) } \\
4 \text { sessions (once weekly); } \\
2,000 \mathrm{sw}, \\
0.25 \mathrm{~mJ} / \mathrm{mm}^{2}, 4 \mathrm{~Hz}\end{array}$ & $\begin{array}{l}\text { IIEF- } 5 \text { change: } \\
5.4 \text { in treatment group; } 0.6 \text { in sham } \\
\text { group } \\
\text { VAS score change: } \\
-5.1 \text { in treatment group; } \\
-2.5 \text { in sham group } \\
\text { Plaque size }\left(\mathrm{cm}^{2}\right) \text { change: } \\
-0.6 \text { in treatment group; } 0.1 \text { in sham } \\
\quad \text { group } \\
\text { Curvature }\left(^{\circ}\right) \text { change: } \\
-1.4 \text { in treatment group; } 1.8 \text { in sham } \\
\text { group }\end{array}$ & None \\
\hline Chitale et $\mathrm{al}^{38}$ & $16 / 20$ & $\begin{array}{l}\text { Stable Peyronie's } \\
\text { disease for }>6 \text { mo. } \\
\text { without previous PD } \\
\text { treatments }\end{array}$ & Sham therapy & 6 mos. & $\begin{array}{l}\text { Device not mentioned } \\
6 \text { sessions (once weekly); } \\
3000 \text { sw, } \\
\text { Energy flux density and } \\
\quad \text { frequency not mentioned }\end{array}$ & $\begin{array}{l}\text { IIEF-5 change: non-significant } \\
\text { VAS score change: non-significant } \\
\text { Plaque size }\left(\mathrm{cm}^{2}\right) \text { change: } \\
\text { Non-significant } \\
\text { Curvature }\left(^{\circ}\right) \text { change: } \\
\text { Non-significant }\end{array}$ & None \\
\hline Palmieri et $a^{140}$ & $50 / 50$ & $\begin{array}{l}\text { Peyronie's disease } \\
\text { for }<12 \text { months, with } \\
\text { painful erections }\end{array}$ & $\begin{array}{l}\text { LISWT + } \\
\quad \text { tadalafil }\end{array}$ & 6 months & $\begin{array}{l}\text { Storz Duolith (Storz Medical } \\
\text { AG, Switzerland) } \\
4 \text { sessions (once weekly); } \\
2000 \mathrm{sw} \text {, } \\
0.25 \mathrm{~mJ} / \mathrm{mm}^{2}, 4 \mathrm{~Hz}\end{array}$ & $\begin{array}{l}\text { IIEF-EF change: significant in both } \\
\text { groups. Higher in the combination } \\
\text { group } \\
\text { VAS score change: } \\
\text { Significant in both groups } \\
\text { Plaque size }\left(\mathrm{cm}^{2}\right) \text { change: } \\
\text { Non-significant } \\
\text { Curvature }\left(^{\circ}\right) \text { change: } \\
\text { Non-significant }\end{array}$ & $\begin{array}{l}\text { Bruising in the } \\
\text { treatment site } \\
\text { (12\%) }\end{array}$ \\
\hline $\begin{array}{l}\text { Hatzichristodoulou } \\
\text { et } \mathrm{al}^{39}\end{array}$ & $51 / 51$ & $\begin{array}{l}\text { Stable Peyronie's } \\
\text { disease for }>3 \text { mo } \\
\text { (onset }>12 \text { mo). Previous } \\
\text { unsuccessful oral medical } \\
\text { therapy }\end{array}$ & Sham therapy & 1 month & $\begin{array}{l}\text { Piezoson } 100 \text { lithotripter } \\
\text { (Richard Wolf, Germany) } \\
6 \text { sessions (once weekly); } \\
2000 \mathrm{sw} \text {, } \\
0.29 \mathrm{~mJ} / \mathrm{mm}^{2}, 3 \mathrm{~Hz}\end{array}$ & $\begin{array}{l}\text { IIEF-5 change: } \\
\text { Not assessed } \\
\text { VAS score change: } \\
-2.5 \text { in treatment group; } \\
-1 \text { in sham group } \\
\text { Plaque size }\left(\mathrm{cm}^{2}\right) \text { change: } \\
\text { Non-significant } \\
\text { Curvature }\left({ }^{\circ}\right) \text { change: } \\
\text { Non-significant }\end{array}$ & $\begin{array}{l}\text { Local petechial } \\
\text { bleeding (80.7\%), } \\
\text { small ecchymosis } \\
\text { (4.9\%) }\end{array}$ \\
\hline
\end{tabular}

IIEF-EF = International Index of Erectile Function-Erectile Function domain; LISWT = low-intensity shockwave therapy; VAS = visual analogue scale. 
Table 5. Randomized clinical trials investigating LISWT for CP/CPPS

\begin{tabular}{|c|c|c|c|c|c|c|}
\hline & $\begin{array}{l}\text { No. treated/ } \\
\text { No. control }\end{array}$ & $\begin{array}{l}\text { Mean age } \\
\text { treated/ } \\
\text { control }\end{array}$ & $\begin{array}{l}\text { Characteristics } \\
\text { of patients }\end{array}$ & Comparator & Study duration & LISWT protocol \\
\hline Zimmermann et $a^{45}$ & $30 / 30$ & $42 / 43$ & $\begin{array}{l}\text { Prostatitis type } \\
\text { IIIB (CPPS) }\end{array}$ & $\begin{array}{l}\text { Sham } \\
\text { procedure }\end{array}$ & 12 wks & $\begin{array}{l}\text { Storz } \\
4 \text { sessions; } \\
3,000 \mathrm{sw} \\
0.25 \mathrm{~mJ} / \mathrm{mm}^{2} \\
120 \mathrm{sw} / \mathrm{min}^{2}\end{array}$ \\
\hline Zeng et $a^{46}$ & $40 / 40$ & $48.7 / 46.3$ & $\begin{array}{l}\text { Prostatitis type } \\
\text { IIIB (CPPS) } \\
\text { refractory to } \\
\text { conventional } \\
\text { therapy }\end{array}$ & $\begin{array}{l}\text { Sham } \\
\text { procedure }\end{array}$ & 12 wks & $\begin{array}{l}\text { Company: not reported } \\
10 \text { sessions } \\
20,000 \mathrm{sw} \\
0.06 \mathrm{~mJ} / \mathrm{mm}^{2} \\
\text { Duration: not reported }\end{array}$ \\
\hline
\end{tabular}

Summary of results

$\%$ change from baseline

CSPI: -16.7 in ESWT vs 4.2 in sham treatment procedure

VAS: -50.0 in ESWT vs 0 in sham treatment procedure

IPSS: -25 in ESWT vs 0 in sham

treatment procedure

$\%$ change from baseline:

CSPI total score: -33 in ESWT vs

0 in sham procedure

Pain (CSPI): -42.3 in ESWT vs 0 in

sham treatment procedure

QoL (CSPI): -42.9 in EWST vs 0.6 in sham treatment procedure

Urination (CSPI): 0 in ESWT vs 0 in sham treatment procedure

\begin{tabular}{|c|c|c|c|c|c|c|c|}
\hline & & & & & & & sham treatment procedure \\
\hline Vahdatpour et $\mathrm{al}^{47}$ & $20 / 20$ & $35.4 / 37.0$ & $\begin{array}{l}\text { Prostatitis type } \\
\text { IIIB (CPPS) }\end{array}$ & $\begin{array}{l}\text { Sham } \\
\text { procedure }\end{array}$ & 12 wks & $\begin{array}{l}\text { Storz } \\
4 \text { sessions. } \\
3,000 \mathrm{sw} \\
0.25 \mathrm{~mJ} / \mathrm{mm}^{2}(0.5 \mathrm{~mJ} / \\
\quad \mathrm{mm}^{2} \text { was added in } \\
\quad \text { each week) } \\
\text { Duration: not reported }\end{array}$ & $\begin{array}{l}\text { \% change from baseline: } \\
\text { CSPI total: }-26.8 \text { in ESWT vs }-0.7 \\
\text { in sham treatment procedure } \\
\text { QoL (CSPI): }-24.7 \text { in ESWT vs } \\
-6.0 \text { in sham treatment } \\
\text { procedure } \\
\text { Pain (CSPI): }-31.2 \text { in ESWT vs } 0.7 \\
\text { in sham treatment procedure } \\
\text { Urination (CSPI): }-19.6 \text { in ESWT } \\
\text { vs }-3.8 \text { in sham treatment } \\
\text { procedure }\end{array}$ \\
\hline Pajovic et al ${ }^{49}$ & $30 / 30$ & $\begin{array}{l}39.4 \\
\text { altogether }\end{array}$ & $\begin{array}{l}\text { Prostatitis type } \\
\text { IIIB (CPPS) } \\
\text { naïve from } \\
\text { therapy }\end{array}$ & $\begin{array}{l}\text { Triple therapy } \\
\text { Doxazosin/ } \\
\text { lbuprofen/ } \\
\text { tiocolchicoside }\end{array}$ & 36 wks & $\begin{array}{l}\text { Triple therapy } \\
\text { Doxazosin/lbuprofen/ } \\
\quad \text { tiocolchicoside + } \\
\text { Lubisone } \\
12 \text { sessions } \\
3,000 \mathrm{sw} \\
0.25 \mathrm{~mJ} / \mathrm{mm}^{2} \\
12 \mathrm{sw} / \mathrm{min}\end{array}$ & $\begin{array}{l}\text { \% change from baseline: } \\
\text { CSPI total: }-56.0 \text { in ESWT + MT } \\
\text { vs }-23.3 \text { in MT } \\
\text { QoL (CSPI): }-55.5 \text { in ESWT + MT } \\
\text { vs }-12.5 \text { in MT } \\
\text { Pain (CSPI): }-57.8 \text { in ESWT + MT } \\
\text { vs }-6.5 \text { in MT } \\
\text { Urination (CSPI): }-63.0 \% \text { in } \\
\text { ESWT + MT vs }-42.2 \text { in MT }\end{array}$ \\
\hline Moayednia et $\mathrm{al}^{48}$ & $40 / 40$ & $34.4 / 36.0$ & $\begin{array}{l}\text { Prostatitis type } \\
\text { IIIB (CPPS) }\end{array}$ & Sham procedure & 24 wks & $\begin{array}{l}\text { Storz } \\
4 \text { sessions } \\
3,000 \mathrm{sw}\end{array}$ & $\begin{array}{l}\text { \% change from baseline: } \\
\text { CSPI total: } 1.5 \text { in ESWT vs }-0.7 \text { in } \\
\text { sham treatment procedure }\end{array}$ \\
\hline
\end{tabular}

(continued) 
Treatment Protocol

No specific recommendation can be made about technical details, including number of pulses, energy, and frequency to be used.

Indication

LISWT can be considered an option for patients with noninflammatory CP/CPPS (NIH-IIIB).

Safety

LISWT as a therapy for CP/CPPS is not associated with any severe adverse events. LISWT is a safe and well-tolerated procedure (level 2; grade B).

\section{Evidence}

\section{Treatment Efficacy}

Present knowledge on the efficacy and tolerability of LISWT in CP/CPPS treatment is based on 5 low-to-moderate quality studies (Table 2); of these, 4 are sham-controlled RCTs, ${ }^{45-48}$ and 1 is a trial comparing LISWT to medical therapy with anti-inflammatory agents and $\alpha$-blockers. ${ }^{49}$ The results of these trials are summarized in Table 5.

In men with CP/CPSS, LISWT showed an improvement of prostatitis-like symptoms and pain after 12 weeks of followup. ${ }^{4-48}$ The degree of the improvement after 12 weeks was quite consistently reported throughout the sham-controlled studies lasting 12 weeks (see Table 4 for details). In particular, the decrease in NIH-CPSI total score was between $17-33 \%$ among the LISWT-treated group and almost null or even increased in the sham-treated men, ${ }^{43-45}$ whereas the pain measures decreased between $30-50 \%$ in the LISWT group, without any change in the sham-treated group. ${ }^{43-45}$ However, these findings were not sustained after 24 weeks, as reported by the longest sham procedure-controlled trial. ${ }^{48}$ In particular in the latter study, initial improvement in prostatitis-like symptoms, including pain, was reported, with a maximum effect after 12 weeks (NIH-CPSI total score $19.74 \pm 1.65$ vs $26.81 \pm 2.91$ in LISWT and sham treatment procedure, respectively; $P<.0001$; NIH-CPSI pain domain $9.15 \pm 0.92$ vs $13.89 \pm 1.47$ in LISWT and sham treatment procedure, respectively; $P<.0001$ ), which was not sustained over time (after 24 weeks: NIH-CPSI total score $26.41 \pm 1.53$ vs $27.00 \pm 1.01$ in LISWT and sham treatment procedure, respectively; $P=.184$; NIH-CPSI pain domain $13.58 \pm 2.12$ vs $13.59 \pm 1.76$ in LISWT and sham treatment procedure, respectively; $P=.982) .{ }^{48}$

A study from Pajovic et al ${ }^{49}$ reported the efficacy of LISWT in addition to a triple therapy with doxazosin/ibuprofen/thiocolchicoside, showing an improvement in prostatitis-like symptoms (24 weeks after the end of treatment: NIH-CPSI total score $13.66 \pm 4.90$ vs $22.46 \pm 5.96$ in combined LISWT + medical treatment and medical treatment alone, respectively; $P<.05$ ) and in pain (NIH-CPSI pain domain $1.86 \pm 0.77$ vs $3.33 \pm$ 1.47 in combined LISWT + medical treatment and medical 
treatment alone, respectively; $P<.05)$ that was maintained for the entire follow-up period. On the other hand, post-voiding residual and peak flow rate were not changed by the concomitant use of LISWT and medical therapy when compared with medical therapy alone. ${ }^{49}$

Evidence from a single-arm study ${ }^{50}$ showed an $81.8 \%$ successful response (at least 6-point decrease in the NIH-CPSI total score) after LISWT, with an average decrease of 3.3 and 6.0 points in the VAS and in the total score of the International Prostatic Symptoms Score after 3 months of follow-up, respectively. Obesity was suggested as a limiting factor to the effectiveness of LISWT, because, among patient non-responders to therapy, the baseline waist circumference was greater than the responders $(92.3 \pm 10.3$ vs $84.7 \pm 6.1$, respectively; $P=.022){ }^{50}$ Current evidence on the effects of LISWT on prostate characteristics at imaging or urodynamic parameters is insufficient to draw meaningful conclusions.

\section{Treatment Protocol}

Concerning the energy delivered for the LISWT, most trials use perineal application with 3,000 pulses, maximum total energy flow density of $0.25 \mathrm{~mJ} / \mathrm{mm}^{2}$ and a frequency of $3 \mathrm{~Hz}$ with a schedule of 1 application weekly for 4 weeks. All generators were used with focused SW. There are currently no studies evaluating linear SW. Unfortunately, there are no available data comparing different treatment protocols with the same SW generator; therefore, a specific protocol cannot be suggested.

\section{Indication}

All available RCTs have been conducted in patients with noninflammatory CP/CPPS (category IIIB according to the NIH classification). There are no available data on the eventual benefits of this treatment among patients with inflammatory or bacterial prostatitis.

\section{Safety}

No major adverse events were reported in all randomized trials assessing LISWT for CP/CPPS, thus, suggesting that this is a safe and well-tolerated procedure.

\section{Value}

The studies on LISWT on CP/CPPS patients are limited and of moderate quality. The panel places a high value on the lack of AEs and on the consistent reporting of improvement in prostatitis-like symptoms and pain up to 12 weeks after the procedure. However, there is no evidence for the maintenance of the improvement over time, because the only sham-procedure controlled study with a follow-up longer than 12 weeks reported a lack of beneficial effect at the end of the study, after an initial improvement measured at 12 weeks. LISWT could be applied in patients with CP/CPPS, either responders or non-responders to conventional therapies, but patients should be advised about the lack of robust evidence and long-term follow-up data.

\section{DISCUSSION}

Although the efficacy of LISWT in improving symptoms in subjects with CP/CPPS could be significant, as denoted by the results obtained in the clinical trials, the studies are limited and with short-term follow-up. In addition, it should be recognized that this treatment represents an off-label approach for treatment of CP/CPPS. Hence, drawing final conclusions on the effectiveness of LISWT on CP/CPPS is still challenging. In addition, the use of LISWT in a research context should be encouraged to obtain further evidence to confirm the presently limited knowledge.

\section{CONCLUSION}

In the last decade, great enthusiasm arose about the application of LISWT in sexual medicine. Evidence from preclinical studies, along with the results of the first RCTs depicted LISWT as a promising therapy for ED. However, those encouraging results were not confirmed in further published trials. In such a case, meta-analysis could be a useful research method to provide an answer to a controversial clinical question. Pooled-data analyses have supported the effectiveness of LISWT in improving the EF of patients with vasculogenic ED; however, these findings should be interpreted with caution, given the bias associated with the included studies and the high heterogeneity in terms of patients' baseline characteristics, treatment protocols, and study design. Even more important, the reported treatment effect is rather small, casting doubts on the actual clinical significance of the observed improvement in psychometric scores.

The application of LISWT in the context of PDs has shown less exciting results. Available data are consistent regarding a lack of efficacy in terms of plaque size reduction and improvement of curvature. However, patients experiencing pain in the acute phase of the disease may benefit from this treatment.

Finally, LISWT could be a feasible option for the improvement of symptoms in men with CP/CPPS. However, this positive effect has been observed in few trials with limited follow-up. The modification of non-subjective parameters has not been adequately studied so far.

New treatment methods must be assessed in terms of both risks and benefits. In the case of LISWT, the benefits are still controversial, although there is consistent evidence supporting the safety and tolerability of this treatment. As such, LISWT could be reasonably proposed as a treatment option in a research context after counseling the patient that its efficacy has not been definitively proven.

After approximately 10 years of intensive clinical research, several answers to important clinical questions are still missing: is LISWT an effective treatment? Is LISWT only effective for a few select patients? What is the best protocol to ensure a higher probability of treatment success? How long does the effect last? Future studies are still needed to address these questions. 
Corresponding Author: Paolo Capogrosso, MD, PhD, FECSM, Università Vita-Salute San Raffaele, Division of Experimental Oncology/Unit of Urology, URI-Urological Research Institute, IRCCS Ospedale San Raffaele, Via Olgettina 60, 20132 Milan, Italy. Tel: 3902 26435506; Fax: 3902 26432969; E-mail: paolo.capogrosso@gmail.com

Conflicts of Interest: The authors report no conflicts of interest.

Funding: None.

\section{STATEMENT OF AUTHORSHIP}

\section{Category 1}

(a) Conception and Design

Paolo Capogrosso; Giulia Rastrelli; Giovanni Corona

(b) Acquisition of Data Paolo Capogrosso; Anders Frey; Christian Fuglesang S. Jensen; Giulia Rastrelli; Giorgio I. Russo; Josep Torremade

(c) Analysis and Interpretation of Data Paolo Capogrosso; Anders Frey; Christian Fuglesang S. Jensen; Giulia Rastrelli; Giorgio I. Russo; Josep Torremade

\section{Category 2}

(a) Drafting the article Paolo Capogrosso; Anders Frey; Christian Fuglesang S. Jensen; Giulia Rastrelli; Giorgio I. Russo; Josep Torremade Writing ? Review \& Editing, PC, GC, MA, IC, CR;

(b) Revising it for Intellectual Content Paolo Capogrosso; Giulia Rastrelli; Maarten Albersen; Ilan Gruenwald; Giovanni Corona

\section{Category 3}

(a) Final Approval of the Completed Article Paolo Capogrosso; Anders Frey; Christian Fuglesang S. Jensen; Giulia Rastrelli; Giorgio I. Russo; Josep Torremade; Maarten Albersen; Ilan Gruenwald; Yacov Reisman; Giovanni Corona

\section{REFERENCES}

1. Becker M, Goetzenich A, Roehl AB, et al. Myocardial effects of local shock wave therapy in a Langendorff model. Ultrasonics 2014;54:131-136.

2. Hayashi D, Kawakami K, Ito K, et al. Low-energy extracorporeal shock wave therapy enhances skin wound healing in diabetic mice: a critical role of endothelial nitric oxide synthase. Wound Repair Regen 2012;20:887-895.

3. Gruenwald I, Kitrey ND, Appel B, et al. Low-intensity extracorporeal shock wave therapy in vascular disease and erectile dysfunction: Theory and outcomes. Sex Med Rev 2013;1:83-90.

4. Rassweiler JJ, Knoll T, Kohrmann KU, et al. Shock wave technology and application: An update. Eur Urol 2011; 59:784-796.

5. Lin G, Reed-Maldonado AB, Wang B, et al. In situ activation of penile progenitor cells with low-intensity extracorporeal shockwave therapy. J Sex Med 2017;14:493-501.
6. Li H, Matheu MP, Sun F, et al. Low-energy shock wave therapy ameliorates erectile dysfunction in a pelvic neurovascular injuries rat model. J Sex Med 2016;13:22-32.

7. Hatzimouratidis K, Eardley I, Giuliano F, et al. EAU guidelines on penile curvature. Eur Urol 2012;62:543-552.

8. Zimmermann R, Cumpanas A, Hoeltl L, et al. Extracorporeal shock-wave therapy for treating chronic pelvic pain syndrome: A feasibility study and the first clinical results. BJU Int 2008; 102:976-980.

9. Srini VS, Reddy RK, Shultz T, et al. Low intensity extracorporeal shockwave therapy for erectile dysfunction: A study in an Indian population. Can J Urol 2015;22:7614-7622.

10. Motil I, Kubis I, Sramkova T. Treatment of vasculogenic erectile dysfunction with Piezowave2 Device. Application of low intensity shockwaves using novel linear shockwave tissue coverage (LSTC-EDR) technique. A prospective, multicentric, placebo-controlled study. Adv Sex Med 2016;6:15-18.

11. Vardi Y, Appel B, Kilchevsky A, et al. Does low intensity extracorporeal shock wave therapy have a physiological effect on erectile function? Short-term results of a randomized, double-blind, sham controlled study. J Urol 2012; 187:1769-1775.

12. Olsen AB, Persiani M, Boie S, et al. Can low-intensity extracorporeal shockwave therapy improve erectile dysfunction? A prospective, randomized, double-blind, placebo-controlled study. Scand J Urol 2015;49:329-333.

13. Yee CH, Chan ES, Hou SS, et al. Extracorporeal shockwave therapy in the treatment of erectile dysfunction: A prospective, randomized, double-blinded, placebo controlled study. Int J Urol 2014;21:1041-1045.

14. Kitrey ND, Gruenwald I, Appel B, et al. Penile low intensity shock wave treatment is able to shift pde5i nonresponders to responders: A double-blind, sham controlled study. J Urol 2016;195:1550-1555.

15. Fojecki GL, Tiessen S, Osther PJ. Effect of low-energy linear shockwave therapy on erectile dysfunction-A double-blinded, sham-controlled, randomized clinical trial. J Sex Med 2017; 14:106-112.

16. Kalyvianakis D, Hatzichristou D. Low-intensity shockwave therapy improves hemodynamic parameters in patients with vasculogenic erectile dysfunction: A triplex ultrasonographybased sham-controlled trial. J Sex Med 2017;14:891-897.

17. Yamaçake KGR, Carneiro F, Cury J, et al. Low-intensity shockwave therapy for erectile dysfunction in kidney transplant recipients. A prospective, randomized, double blinded, sham-controlled study with evaluation by penile Doppler ultrasonography. Int J Impot Res 2019;31:195-203.

18. Fojecki GL, Tiessen S, Osther PJS. Effect of linear low-intensity extracorporeal shockwave therapy for erectile dysfunction-12month follow-up of a randomized, double-blinded, shamcontrolled study. Sex Med 2018;6:1-7.

19. Angulo JC, Arance I, de Las Heras MM, et al. Efficacy of lowintensity shock wave therapy for erectile dysfunction: A systematic review and meta-analysis. Actas Urol Esp 2017; 41:479-490. 
20. Lu Z, Lin G, Reed-Maldonado A, et al. Low-intensity extracorporeal shock wave treatment improves erectile function: A systematic review and meta-analysis. Eur Urol 2017;71:223-233.

21. Man L, Li G. Low-intensity extracorporeal shock wave therapy for erectile dysfunction: A systematic review and meta-analysis. Urology 2018;119:97-103.

22. Clavijo RI, Kohn TP, Kohn JR, et al. Effects of low-intensity extracorporeal shockwave therapy on erectile dysfunction: A systematic review and meta-analysis. J Sex Med 2017; 14:27-35.

23. Zou ZJ, Tang LY, Liu ZH, et al. Short-term efficacy and safety of low-intensity extracorporeal shock wave therapy in erectile dysfunction: A systematic review and meta-analysis. Int Braz J Urol 2017;43:805-821.

24. Kalyvianakis D, Memmos E, Mykoniatis I, et al. Low-intensity shockwave therapy for erectile dysfunction: A randomized clinical trial comparing 2 treatment protocols and the impact of repeating treatment. J Sex Med 2018;15:334-345.

25. Kitrey ND, Vardi Y, Appel B, et al. Low intensity shock wave treatment for erectile dysfunction-How long does the effect last? J Urol 2018;200:167-170.

26. Hisasue S, China T, Horiuchi A, et al. Impact of aging and comorbidity on the efficacy of low-intensity shock wave therapy for erectile dysfunction. Int J Urol 2016;23:80-84.

27. Ayala HAC, Cuartas JPS, Cleves DC. Impact on the quality of erections after completing a low-intensity extracorporeal shock wave treatment cycle on a group of 710 patients. Adv Urol 2017;2017:1843687.

28. Tsai CC, Wang CJ, Lee YC, et al. Low-intensity extracorporeal shockwave therapy can improve erectile function in patients who failed to respond to phosphodiesterase type 5 inhibitors. Am J Mens Health 2017;11:1781-1790.

29. Vardi Y, Appel B, Jacob G, et al. Can low-intensity extracorporeal shockwave therapy improve erectile function? A 6month follow-up pilot study in patients with organic erectile dysfunction. Eur Urol 2010;58:243-248.

30. Gruenwald I, Appel B, Vardi Y. Low-intensity extracorporeal shock wave therapy-A novel effective treatment for erectile dysfunction in severe ED patients who respond poorly to PDE5 inhibitor therapy. J Sex Med 2012;9:259-264.

31. Reisman Y, Hind A, Varaneckas A, et al. Initial experience with linear focused shockwave treatment for erectile dysfunction: A 6-month follow-up pilot study. Int J Impot Res 2015;27:108-112.

32. Chung E, Cartmill R. Evaluation of clinical efficacy, safety and patient satisfaction rate after low-intensity extracorporeal shockwave therapy for the treatment of male erectile dysfunction: An Australian first open-label single-arm prospective clinical trial. BJU Int 2015;115(Suppl. 5):46-49.

33. Ruffo A, Capece M, Prezioso D, et al. Safety and efficacy of low intensity shockwave (LISW) treatment in patients with erectile dysfunction. Int Braz J Urol 2015;41:967-974.
34. Pelayo-Nieto M, Linden-Castro E, Alias-Melgar A, et al. Linear shock wave therapy in the treatment of erectile dysfunction. Actas Urol Esp 2015;39:456-459.

35. Frey A, Sonksen J, Fode M. Low-intensity extracorporeal shockwave therapy in the treatment of postprostatectomy erectile dysfunction: A pilot study. Scand J Urol 2016; 50:123-127.

36. Bechara A, Casabé A, De Bonis W, et al. Twelve-month efficacy and safety of low-intensity shockwave therapy for erectile dysfunction in patients who do not respond to phosphodiesterase type 5 inhibitors. Sex Med 2016;4:e225-e232.

37. Palmieri A, Imbimbo C, Longo $N$, et al. A first prospective, randomized, double-blind, placebo-controlled clinical trial evaluating extracorporeal shock wave therapy for the treatment of Peyronie's disease. Eur Urol 2009;56:363-369.

38. Chitale S, Morsey M, Swift L, et al. Limited shock wave therapy vs sham treatment in men with Peyronie's disease: Results of a prospective randomized controlled double-blind trial. BJU Int 2010;106:1352-1356.

39. Hatzichristodoulou G, Meisner C, Gschwend JE, et al. Extracorporeal shock wave therapy in Peyronie's disease: Results of a placebo-controlled, prospective, randomized, single-blind study. J Sex Med 2013;10:2815-2821.

40. Palmieri A, Imbimbo C, Creta M, et al. Tadalafil once daily and extracorporeal shock wave therapy in the management of patients with Peyronie's disease and erectile dysfunction: Results from a prospective randomized trial. Int J Androl 2012;35:190-195.

41. Gao L, Qian S, Tang Z, et al. A meta-analysis of extracorporeal shock wave therapy for Peyronie's disease. Int J Impot Res 2016;28:161-166.

42. Mirone $V$, Imbimbo C, Palmieri A, et al. Our experience on the association of a new physical and medical therapy in patients suffering from induratio penis plastica. Eur Urol 1999;36:327-330.

43. Hauck EW, Altinkilic BM, Ludwig M, et al. Extracorporal shock wave therapy in the treatment of Peyronie's disease. First results of a case-controlled approach. Eur Urol 2000;38:663669; discussion 670.

44. Poulakis V, Skriapas K, de Vries R, et al. Extracorporeal shockwave therapy for Peyronie's disease: An alternative treatment? Asian J Androl 2006;8:361-366.

45. Zimmermann R, Cumpanas A, Miclea F, et al. Extracorporeal shock wave therapy for the treatment of chronic pelvic pain syndrome in males: A randomised, double-blind, placebocontrolled study. Eur Urol 2009;56:418-424.

46. Zeng XY, Liang C, Ye ZQ. Extracorporeal shock wave treatment for non-inflammatory chronic pelvic pain syndrome: A prospective, randomized and sham-controlled study. Chin Med J (Engl) 2012;125:114-118.

47. Vahdatpour B, Alizadeh F, Moayednia A, et al. Efficacy of extracorporeal shock wave therapy for the treatment of chronic pelvic pain syndrome: A randomized, controlled trial. ISRN Urol 2013;2013:972601. 
48. Moayednia A, Haghdani S, Khosrawi S, et al. Long-term effect of extracorporeal shock wave therapy on the treatment of chronic pelvic pain syndrome due to non bacterial prostatitis. J Res Med Sci 2014;19:293-296.

49. Pajovic B, Radojevic N, Dimitrovski A, et al. Comparison of the efficiency of combined extracorporeal shock-wave therapy and triple therapy versus triple therapy itself in Category III B chronic pelvic pain syndrome (CPPS). Aging Male 2016; 19:202-207.

50. Guu SJ, Geng JH, Chao IT, et al. Efficacy of low-intensity extracorporeal shock wave therapy on men with chronic pelvic pain syndrome refractory to 3-As therapy. Am J Mens Health 2018;12:441-452. 